05.6;09.1

\title{
Радиационная деградация сцинтилляторов на основе LiF : W
}

\author{
(ㄷ Г. Гэ, В.И. Корепанов, П.В. Петикарь \\ Национальный исследовательский Томский политехнический университет, Томск, Россия \\ E-mail: Korepanov@tpu.ru
}

Поступило в Редакцию 10 апреля 2019г.

В окончательной редакции 10 апреля 2019г.

Принято к публикации 17 апреля 2019г.

\begin{abstract}
Изучены закономерности и причины изменения спектрально-кинетических характеристик катодолюминесценции кристаллов $\mathrm{LiF}: \mathrm{W}$ при облучении наносекундными электронными импульсами. Установлен вклад в искажение катодолюминесценции процессов преобразования дорадиационной дефектности и накопления центров окраски. Определены оптимальные условия эксплуатации сцинтилляторов LiF: W. Oбнаружено, что предварительное облучение $\mathrm{LiF}: \mathrm{W}$ дозами $10^{3}-10^{4} \mathrm{~Gy}$ приводит к увеличению интенсивности катодолюминесценции в $1.5-2$ раза („эффект малых доз“).
\end{abstract}

Ключевые слова: Катодолюминесценция, радиационная деградация, сцинтилляторы, LiF:W, дефекты.

Объектом исследования настоящей работы является активаторная люминесценция кристаллов LiF:W. Кристаллы LiF с примесями, в том числе W, могут быть эффективными сцинтилляторами для медицинской диагностики, регистрации частиц темной материи и других областей [1-3]. Цель работы - установить основные закономерности и причины радиационной деградации катодолюминесценции $\mathrm{LiF}: \mathrm{W}$, определить оптимальные условия эксплуатации кристалла в поле радиации, способы повышения эффективности.

Облучение образцов, возбуждение импульсной катодолюминесценции (ИКЛ) и стационарной катодолюминесценции (КЛ) производились пучком электронов длительностью $10 \mathrm{~ns}$ (поглощенная доза за импульс 200-250 Gy) со средней энергией $200 \mathrm{keV}$ при температурах 20-300 K. Измерение спектров КЛ проводилось волоконно-оптическим спектрометром AvaSpec 3648-USB2 за один импульс электронов после облучения серией импульсов (различными дозами). Спектры ИКЛ были измерены с временны́м разрешением $7 \mathrm{~ns}$.

Радиационная деградация - важнейшая эксплуатационная характеристика сцинтилляторов. Она характеризуется изменениями спектров излучения, длительности послесвечения, светового выхода и других параметров.

Типичные спектры активаторной КЛ $\mathrm{LiF}: \mathrm{WO}_{3}$ представлены на рис. 1 и состоят из перекрывающихся полос 3.1 и $2.64 \mathrm{eV}$, которые обусловлены излучательными переходами в кислородных центрах $\mathrm{O}^{2-}-V_{a}$ (кислород-анионная вакансия) и центрах $\mathrm{O}^{2-}-V_{a}$, возмущенных примесью металла, соответственно [4].

При $T>200 \mathrm{~K}$ после облучения электронами в спектрах КЛ появляется характерный „провал“ в области энергий квантов $E=2.77 \mathrm{eV}$ (рис. 1,a), связанный с поглощением КЛ накопленными $F_{2}$-центрами окраски [5]. При $T<200 \mathrm{~K}$ даже длительное облучение не приводит к появлению „провала“ (рис. 1,b). Однако искажение спектра люминесценции есть и связа- но с поглощением части активаторной КЛ центрами окраски (ЦО) $F_{2}\left(E_{\max }=2.77 \mathrm{eV}\right), F_{3}^{+}\left(E_{\max }=2.74 \mathrm{eV}\right)$, $V_{k}\left(E_{\max }=3.54 \mathrm{eV}\right)$. Суммарный спектр поглощения этими центрами не имеет узких полос в диапазоне 3.6-2.1 eV [6], и спектр КЛ даже при больших дозах облучения не имеет выраженных „провалов“.

Таким образом, при любых температурах с ростом дозы электронного облучения происходит искажение спектра и интенсивности активаторной КЛ в результате поглощения накопленными ЦО и появления дополнительных каналов диссипации поглощенной энергии радиации (захват первичных дефектов центрами окраски). Характер и степень искажения зависят от температуры, дозы облучения, типа и количества накопленных ЦО.

На основе исследований ИКЛ кристаллов $\mathrm{LiF}: \mathrm{WO}_{3}$ с наносекундным временны́м разрешением [5] установлено, что облучение приводит к накоплению молекулярных ионов $\mathrm{O}_{2}^{-}$по реакции $\mathrm{OH}^{-} \rightarrow \mathrm{O}_{2}^{-}$. Люминесценция ионов $\mathrm{O}_{2}^{-}$состоит из серий узких полос, а затухание происходит в наносекундном временно́м диапазоне. Спектр активаторной люминесценции широкая полоса (рис. 1), затухающая по экспоненциальному закону с характеристическим временем затухания $\tau=38 \mu \mathrm{s}$ при $300 \mathrm{~K}$. Спектральные диапазоны активаторного излучения и излучения, обусловленного ионами $\mathrm{O}_{2}^{-}$, близки, но высвеченная светосумма ИКЛ ионов $\mathrm{O}_{2}^{-}$на порядок меньше, чем ИКЛ активаторного свечения. Поэтому вклад КЛ молекулы $\mathrm{O}_{2}^{-}$в искажение параметров сцинтилляций $\mathrm{LiF}: \mathrm{WO}_{3}$ в микросекундном временно́м диапазоне невелик. Процесс преобразования $\mathrm{OH}^{-} \rightarrow \mathrm{O}_{2}^{-}$эффективен при температурах выше $200 \mathrm{~K}$, а интенсивность люминесценции выше при низких температурах. Поэтому использование сцинтилляторов при низких температурах существенно снижает влияние этого эффекта.

При больших дозах искажение спектральнокинетических характеристик излучения кристаллов $\mathrm{LiF}: \mathrm{WO}_{3}$ происходит за счет появления люминесценции 

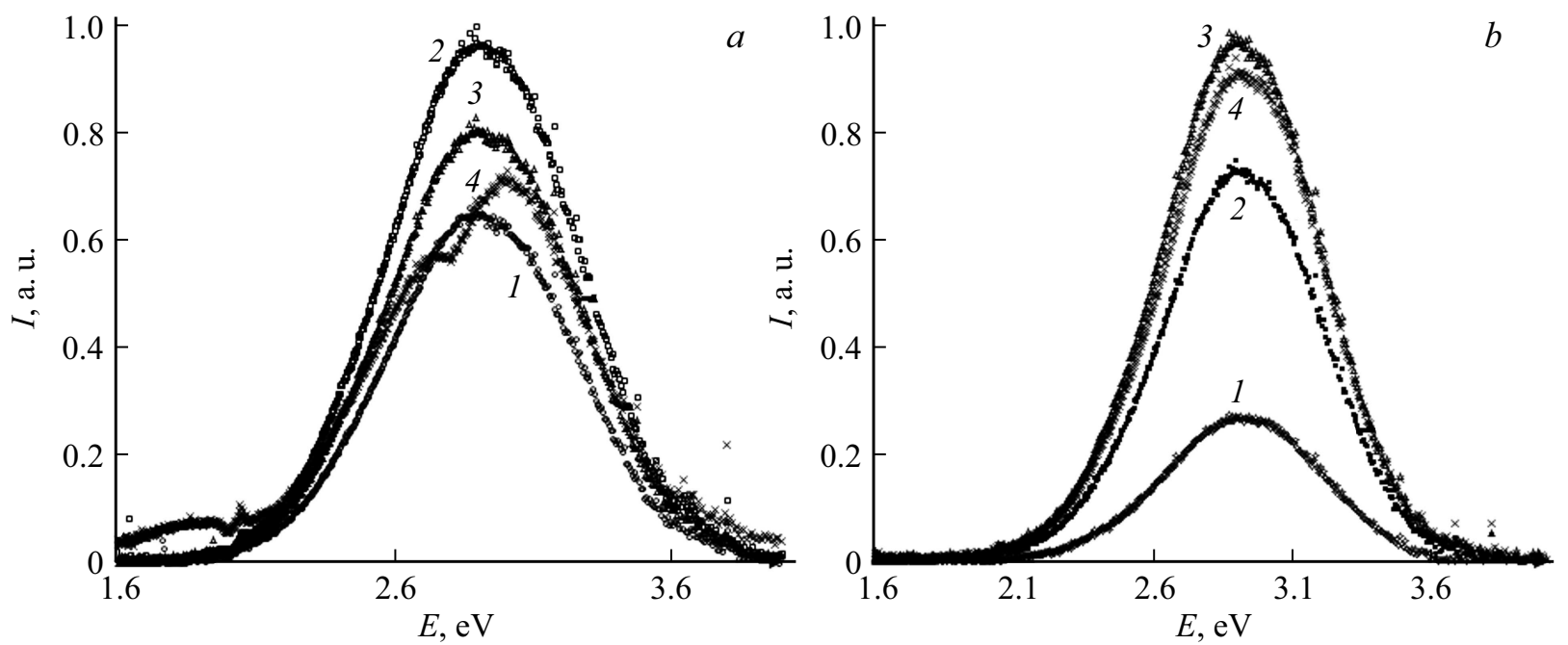

Рис. 1. Спектры КЛ кристаллов $\mathrm{LiF}: \mathrm{WO}_{3}$ после облучения различными дозами импульсного электронного облучения при 300 (a) и $100 \mathrm{~K}(b) .1-250 \mathrm{~Gy}, 2-750 \mathrm{~Gy}, 3-1.5 \mathrm{kGy}, 4-20 \mathrm{kGy}$.
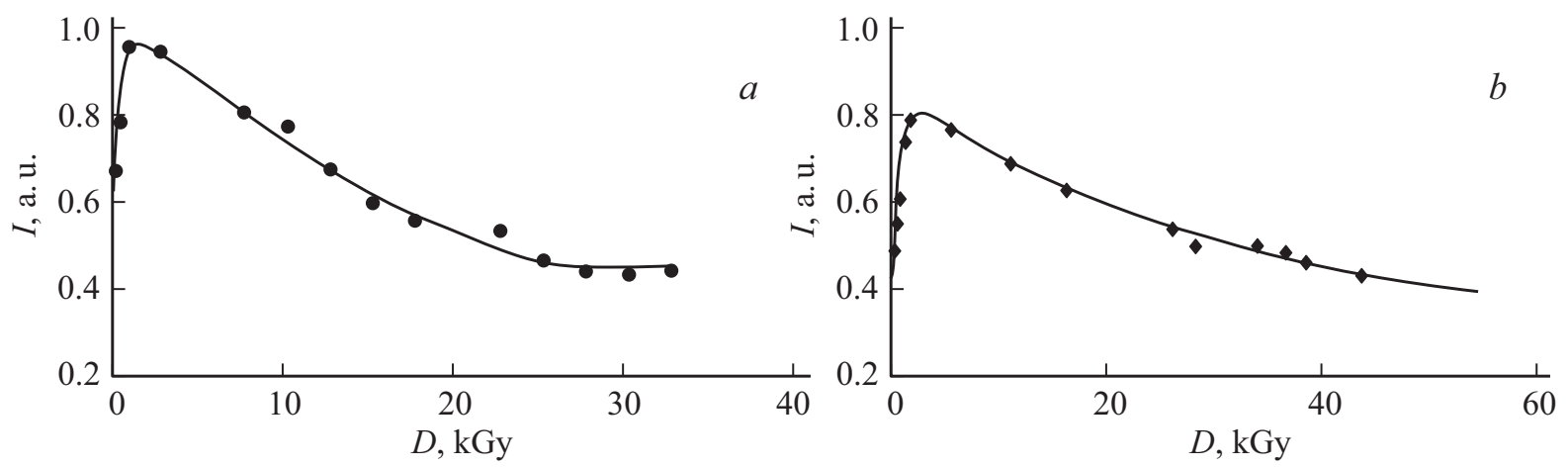

Рис. 2. Изменение интенсивности катодолюминесценции кристаллов $\mathrm{LiF}: \mathrm{WO}_{3}$ при $E=2.8 \mathrm{eV}$ в зависимости от дозы импульсного электронного облучения при $300(a)$ и $100 \mathrm{~K}(b)$.

ЦО. Например, в облученном кристалле можно наблюдать ИКЛ $F_{2}$-центров, кинетика затухания которой представлена собственным наносекундным свечением и свечением с $\tau=38 \mu \mathrm{s}$, совпадающим с $\tau$ активаторной ИКЛ. Появление второго компонента связано с фотовозбуждением $F_{2}$-центров активаторной КЛ. Поэтому с ростом дозы облучения растет вклад люминесценции ЦО и изменяются кинетические характеристики затухания их свечения. Однако люминесценция $F_{2}$-центров находится за пределами спектрального диапазона активаторного свечения.

Кинетика (дозовые зависимости) изменения интенсивности КЛ кристаллов $\mathrm{LiF}: \mathrm{WO}_{3}$ с энергией квантов $E=2.8 \mathrm{eV}$ приведена на рис. 2. Эти зависимости качественно демонстрируют характер и степень деградации параметров сцинтилляций в $\mathrm{LiF}: \mathrm{WO}_{3}$ в процессе их эксплуатации. Кинетика состоит из двух стадий (нарастания и уменьшения). Рост интенсивности КЛ происходит в пределах поглощенных доз $10^{3}-10^{4} \mathrm{~Gy}$. Дальнейшее облучение приводит к ее уменьшению. Вид кинетики характерен для всех температур в пределах всего спектра активаторного свечения. При температурах, близких к комнатной, эффективность нарастания КЛ значительно ниже, чем при низких температурах.

Нарастание интенсивности КЛ при малых дозах облучения („эффект малых доз“) обусловлено взаимодействием дорадиационной дефектности с первичными радиационными дефектами, например парами Френкеля $(F, H$-парами). Об этом свидетельствует тот факт, что дозы, при которых происходит насышение интенсивности активаторной КЛ, и концентрации накопленных ЦО в $\mathrm{LiF}: \mathrm{WO}_{3}$ на быстрой стадии [6] близки $\left(10^{3}-10^{4} \mathrm{~Gy}\right)$. Быстрая стадия накопления ЦО в ионных кристаллах связана с дорадиационной дефектностью и обусловлена появлением в решетке дополнительных ловушек для $H$-центров [6]. При выращивании фторида лития с примесями металлов в кристалле создаются комплексы дефектов, компенсирующие избыточный заряд примеси, например кислородные центры $[4,7,8]$. Такие комплексы могут быть эффективными ловушками электронных $\left(e^{-}, p^{+}\right.$-пары) и ионных $(F, H$-пары) возбуждений. 


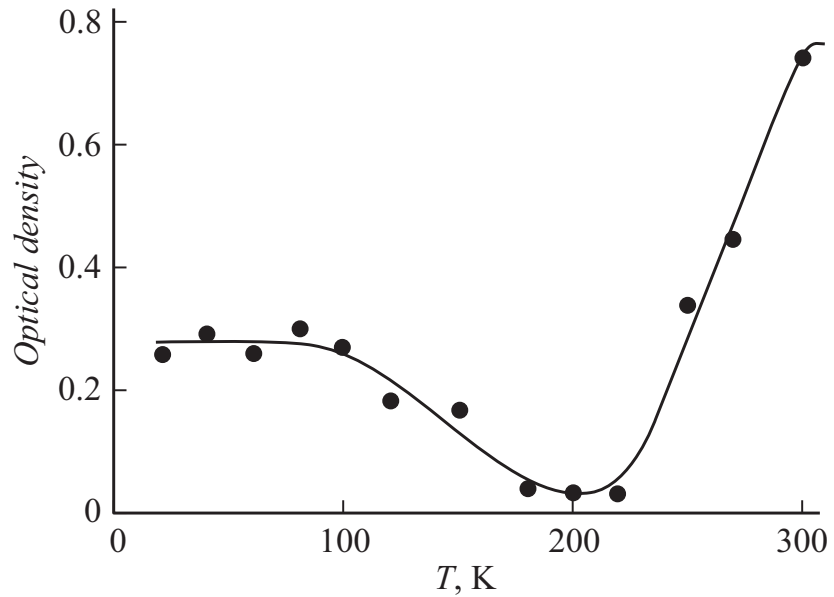

Рис. 3. Температурная зависимость эффективности накопления $F_{2}$-центров в кристаллах $\mathrm{LiF}: \mathrm{WO}_{3}$.

В поле радиации при малых дозах $\left(10^{3}-10^{4} \mathrm{~Gy}\right)$ происходит преобразование дорадиационных дефектов, их стабилизация, количество свободных ловушек для электронных и ионных возбуждений уменьшается, что приводит к насыщению эффективности накопления ЦО и прекращению роста интенсивности КЛ в $\mathrm{LiF}: \mathrm{WO}_{3}$. Однако детали процессов, приводящих к „эффекту малых доз“, требуют дополнительных исследований. Отметим, что преобразование не связано с реакцией $\mathrm{OH}^{-} \rightarrow \mathrm{O}_{2}^{-}$, так как при понижении температуры скорость преобразования $\mathrm{OH}^{-} \rightarrow \mathrm{O}_{2}^{-}$уменьшается [5], а эффективность нарастания КЛ на первой стадии увеличивается.

Уменьшение интенсивности КЛ в $\mathrm{LiF}: \mathrm{WO}_{3}$ связано с ЦО, кинетика накопления которых состоит из быстрой (отсутствует в $\mathrm{LiF}$ ) и медленной (присутствует в чистом $\mathrm{LiF}$ ) стадий при всех температурах [6]. Скорость накопления всех типов ЦО на быстрой стадии $\left(0-10^{4} \mathrm{~Gy}\right)$ при всех температурах на порядок выше. Этот фактор увеличивает эффективность радиационной деградации активаторного свечения как за счет поглощения ЦО, так и за счет появления дополнительного канала поглощения энергии радиации. Наименьшая эффективность накопления ЦО приходится на область $175-225 \mathrm{~K}$ (рис. 3), и этот диапазон является оптимальным для эксплуатации сцинтилляторов на основе $\mathrm{LiF}: \mathrm{WO}_{3}$.

С учетом изложенного выше можно сделать следующие выводы.

1. Основными видами и причинами радиационной деградации сцинтилляторов на основе $\mathrm{LiF}: \mathrm{WO}_{3}$ являются:

- искажение спектров активаторной КЛ $\mathrm{LiF}: \mathrm{WO}_{3}$ за счет поглощения центрами окраски, появления люминесценции $\mathrm{O}_{2}^{-}$-центров, люминесценции центров окраски, в том числе при фотовозбуждении;

- изменение кинетических параметров ИКЛ за счет появления люминесценции $\mathrm{O}_{2}^{-}$-центров и фотовозбуждения центров окраски;
- изменение интенсивности активаторной люминесценции за счет поглощения центрами окраски и появления дополнительных каналов поглощения энергии радиации.

2. Основной вклад в искажение КЛ вносят преобразование дорадиационной дефектности, сопровождающееся ростом интенсивности люминесценции („эффект малых доз“), и накопление центров окраски, сопровождающееся уменьшением интенсивности люминесценции (,эффект больших доз“").

3. Среди практических рекомендаций по оптимизации параметров КЛ $\mathrm{LiF}: \mathrm{WO}_{3}$ отметим следующие:

- при выращивании кристаллов нужно создавать условия, минимизирующие накопление ионов $\mathrm{OH}^{-}$;

- необходимо предварительное облучение малыми дозами до $10^{4} \mathrm{~Gy}$, что приведет к увеличению интенсивности КЛ;

- оптимальной температурной областью эксплуатации является $175-225 \mathrm{~K}$, так как в этом интервале минимальны как эффективность накопления центров окраски, так и эффективность образования ионов $\mathrm{O}_{2}^{-}$.

\section{Конфрликт интересов}

Авторы заявляют, что у них нет конфликта интересов.

\section{Список литературы}

[1] Kawaguchi N., Kawano N., Okada G., Yanagida T. // Sensors Mater. 2017. V. 29. N 10. P. 1431-1438.

[2] Абдурашитов Д., Гектин А., Непомнящих А., Раджабов Е., Ширан Н. Возможности применения сцинтилляционных кристаллов $\mathrm{LiF}$ как детекторов частиц темной материи // ИСМАРТ-2012. Дубна, 2012.

[3] Kurosawa S., Yamaji A., Pejchal J., Yokota Y., Ohashi Y., Kamada K., Yoshikawa A. // J. Mater. Sci. 2017. V. 52. N 10. P. 5531-5536.

[4] Korepanov V.I., Petikar P.V., Ge G., Lipovka A.A. // Key Eng. Mater. 2017. V. 769. P. 141-145.

[5] Lisitsyna L.A., Korepanov V.I., Lisitsyn V.M., Petikar P.V., Kasymkanova R.N., Esilbaev D.B. // Proc. of Higher Education Physics. 2012. V. 55. N 11/3. P. 95-99.

[6] Корепанов В.И., Петикарь П.В. // Изв. вузов. Физика. 2015. Т. 58. № 6-2. С. 147-151.

[7] Небогин С.А., Брюквина Л.И., Иванов Н.А., Глазунов Д.С. // ФTT. 2017. Т. 59. В. 6. C. 1118-1124.

[8] Mysovsky A.S., Sushko P.V., Radzhabov E.A., Reichling M., Shluger A.L. // Phys. Rev. B. 2011. V. 84. N 6. P. 064133. 